\title{
MULTIPLATFORM APPROACH TO MOBILE LASER SCANNING
}

\author{
Antero Kukko $^{\text {a, } * \text {, Harri Kaartinen }}{ }^{\text {a }}$, Juha Hyyppä ${ }^{\text {a }}$, Yuwei Chen ${ }^{\text {b }}$ \\ ${ }^{\text {a }}$ Dept. of Remote Sensing and Photogrammetry, Finnish Geodetic Institute, Masala, Finland - Antero.Kukko@fgi.fi, \\ Harri.Kaartinen@fgi.fi, Juha.Hyyppä@fgi.fi \\ www.fgi.fi/mobimap \\ ${ }^{\mathrm{b}}$ Dept. of Navigation and Positioning, Finnish Geodetic Institute, Masala, Finland - Yuwei.Chen@fgi.fi,
}

Inter-Commission Working Group V/I

KEY WORDS: GPS/INS, Platforms, Laser scanning, Point Cloud, Mobile, Geometric

\begin{abstract}
:
Mobile laser scanning is an emerging technology for capturing three-dimensional information from the surrounding objects. With state of the art sensors the achieved point cloud could capture fine details of the surroundings with good accuracy and effectiveness. Many of the applications deal with the civil engineering purposes in urban areas for traffic and city planning and modelling. In this article we present multiplatform mobile laser scanning solutions for mapping applications that require mobility in various terrains and river environments but yet produce high density point clouds with good reliability and accuracy. The ROAMER mobile laser scanning system was deployed in multitude of tasks from urban areas to climate research. The paper also introduces a completely new backpack Akhka platform for mobile lidar mapping of areas where wheeled vehicles cannot operate. The sensor set is the same in all of the approaches, but the carrying vessel was selected according to the application. This was possible thanks to a relatively light and compact yet simple design of the system. ROAMER system is one of the few high-end MLS systems that are easily adaptable to various platforms. In addition to technical description of the system we discuss the practical performance of the solutions through various applications in the fields of urban mapping, fluvial geomorphology, snow cover characterization and climate change monitoring.
\end{abstract}

\section{INTRODUCTION}

There has been an increasing interest in vehicle-based (mobile) surveying applications of laser scanning since the beginning of the $21^{\text {st }}$ century as laser scanners started to be incorporated into the so called mobile mapping systems (MMS)(Lehtomäki et al., 2011). Lidar based mobile mapping system, a.k.a. mobile laser scanning (MLS), produces three-dimensional points from the surrounding objects with two-dimensional profiling scanners, the third dimension is achieved by the movement of the vehicle and motion-tracking navigation devices. The survey is conducted as the ground vehicle moves around while the navigation system, typically based on global navigation satellite system (GNSS) and inertial navigation system (INS), tracks the vehicle trajectory and attitude for producing $3 \mathrm{D}$ point cloud out of the range information from the onboard scanners. Analogous to airborne laser scanning (ALS) the characteristics, e.g., density, point pattern and distribution, of the obtained point cloud depend largely on the sensor arrangement on the platform, and the sensor properties, such as point measurement rate, scan frequency, and wavelength (see e.g., Kukko and Hyyppä, 2009, Yoo et al., 2010, Cahalane et al., 2010). Different layouts and approaches can be found in numerous papers ( e.g., Yoo et al., 2010, Gräfe, 2007, Hesse and Kuttere, 2007, El-Sheimy, 2005, Kukko et al., 2007, Kukko et al., 2009, Petrie, 2010). The applications of MLS to environmental remote sensing have thus far been focused on vegetation studies and hydrology (Barber and Mills, 2007, Alho et al., 2009, Alho et al., 2011, Vaaja et al., 2011), while a number of applications have been presented for urban road environment (Lehtomäki et al. 2011, Kukko et al., 2009, Jaakkola et al, 2008, Lehtomäki et al., 2010).
Mobile mapping is expected to provide ease in mobilization and low cost compared to airborne laser scanning. This is especially attractive in projects comprising small or limited areas and specific tasks. In addition, the sensor layout of a MMS and other surveying arrangement could be adjusted more freely in comparison to the airborne laser scanning (ALS) to meet task specific requirements. 3D models processed from the data collected by an MLS offer high resolution visualization and surface analysis, which cannot be achieved from ALS and/or aerial images since they provide coarser rendition with considerably less point density and precision.

Considering the data acquisition compared to the data from stationary TLS, MLS provides high efficiency and precise way for generating dense point clouds, and mobility makes it more suitable for surveying and modelling of large areas. This is especially prominent in cases where ground validation is needed for, e.g., airborne experiments or in the areas covered by Earth observing satellites (see Kaasalainen et al., 2008, Connor et al., 2009). Additionally, stationary data collection has several weak points; poor efficiency in data acquisition due to redundancy, difficult planning for viewpoints and directions in data acquisition when measuring large and complicated scenes, and the complexity of a registration method that could succeed in automated registering of all kinds of range data (Zhao and Shibasaki, 2003, Kukko, 2009).

Most of the 3D mapping applications could benefit from the accuracy and efficiency of the mobile laser scanning technology compared to the traditional mapping methods utilizing digital aerial images and airborne laser scanning as well as geodetic measurements with totalstations and terrestrial lasers. The

\footnotetext{
* Corresponding author.
} 
advantages of MLS data for producing high resolution 3D models are obvious, as is demonstrated by the examples later in this issue.

Current version of the ROAMER, a single-scanner mobile mapping system for road environment mapping was internationally introduced in (Kukko et al., 2007), and offers the possibility to use vertical or tilted scanning plane for adapting the system for appropriate 3D point acquisition in different tasks. In this paper a multiplatform approach used to operate the ROAMER, and a completely new backpack Akhka MLS system are described and discussed. Results from an evaluation of the ROAMER data accuracy against a permanent MLS test field are given, and an accuracy assessment of the Akhka data against implemented in situ target field method is performed.

\section{MULTIPLATFORM MLS}

ROAMER mobile laser scanning system of the Finnish geodetic Institute seen in Figure 1 is a high-end surveying device for producing accurate, dense and precise point clouds for threedimensional detection, localization, modelling, analysis and monitoring of artificial and natural objects and processes. The initial goals for the system were to develop a system that would maximize the automation of feature extraction at the post processing phase (Kukko et al., 2007). Additionally, the system should be a moving laboratory flexible for various applications. Table 1 summarizes the current ROAMER equipment and the main data acquisition parameters that are operator selectable to adapt the data acquisition appropriately to the task at hand.

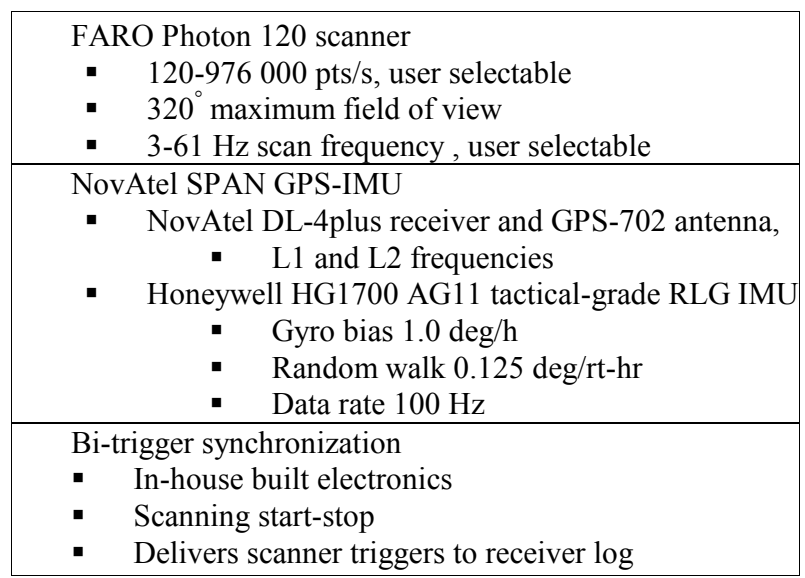

Table 1. ROAMER MLS system equipment and characteristics.

ROAMER is a DC powered compact unit that can be installed on various carrier platforms for mobility and requirements set by application. Operation time of the system in battery power is several hours at a time, whereas in vehicles the DC output can be used as power source for continuous operation. Data recording computers are rugged laptops.

The laser scanning unit in ROAMER is FARO Photon 120 that uses $785 \mathrm{~nm}$ laser with power of $20 \mathrm{~mW}$ (Laser class 3R). The scanner operates up to $976 \mathrm{kHz}$ point measurement frequency and $61 \mathrm{~Hz}$ maximum profile measurement rate with 153 meter ambiguity interval of the phase-shift ranging. Laser beam diameter at the beam exit of the scanner is $3.3 \mathrm{~mm}$ and the beam spreads according to $0.16 \mathrm{mrad}$ divergence angle. That results to laser footprint size of $20 \mathrm{~mm}$ at $100 \mathrm{~m}$ range from the scanner allowing together with the precise range measurement, detailed $3 \mathrm{D}$ measurements from the objects.

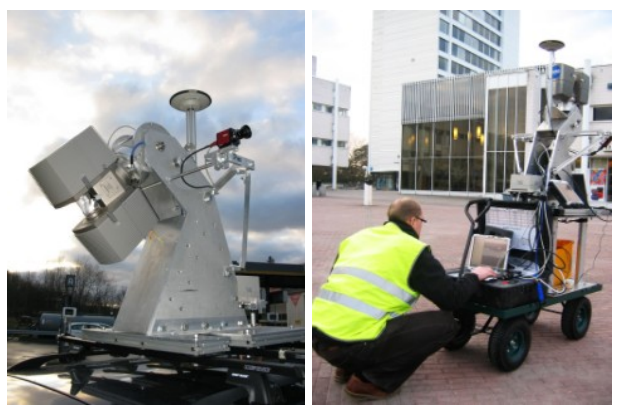

Figure 1. Left: ROAMER as a vehicle MLS (Photo courtesy Hannu Hyyppä). Right: Trolley MLS installation.

\subsection{ROAMER - Vehicle MLS for urban mapping}

Urban modelling is today a field of the most effort by the global enterprises pursuing for $3 \mathrm{D}$ data products. Mobile mapping is the only technology to offer the pedestrian point of view to the process with sufficient level of detail for personal navigation in mobile handheld devices as introduced e.g., in 3D-NAVIEXPO project (Liu et al., 2010). Vehicle MLS is currently widely used in the context of urban area mapping, as the vehicle platform provides sufficient speed along with the traffic, and enough room for the equipment needed for the surveying.

Vehicle MLS data from streets contain typically intensity information about road paintings and geometric information about buildings, bridges, pavement, pedestrian structures and islands, man holes, curbs, poles, signs and pylons, as seen in Figure 2. Intensity readings can be utilized in addition to the geometric information for automatic extraction of different target types from the point clouds (Jaakkola et al., 2008). Detection and inventory of utility poles, traffic sings and lamp posts is a good example of utilizing MLS in urban infrastructure maintenance as studied in (Lehtomäki et al., 2010). MLS data could also provide up-to-date information of power lines and other open air infrastructure, railway facilities etc.

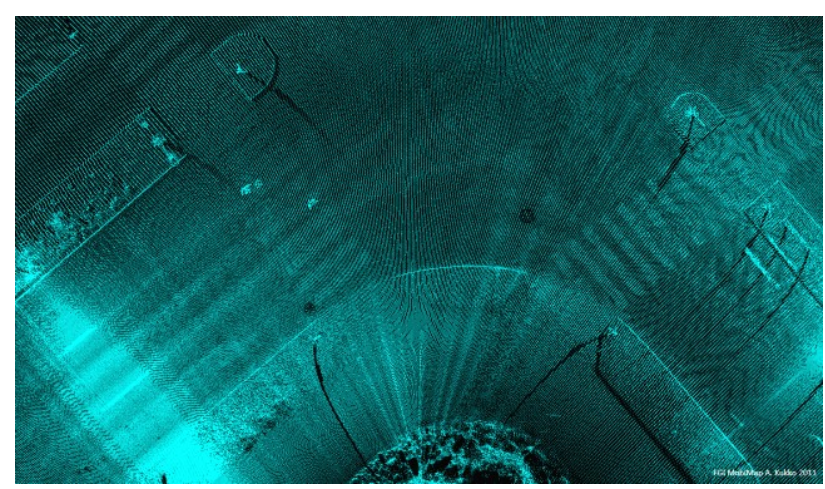

Figure 2. Vehicle MLS data from a street corner captures geometry of the streets, road paintings and other road environment structures in high detail.

The scanning geometry and point density for a mobile lidar is different from the airborne laser scanning. For ROAMER the along-track profile spacing is shorter than 0.5 meter even for the speed up to $70-80 \mathrm{~km} / \mathrm{h}$ when high mirror speeds are used. With $61 \mathrm{~Hz}$ scan frequency the profile interval becomes better than $20 \mathrm{~cm}$ when the speed is kept below $40 \mathrm{~km} / \mathrm{h}$, and still the point resolution along the profile is $15-30 \mathrm{~mm}$, which is sufficient for the practical ranges of $20-40 \mathrm{~m}$ in the urban environment. In the end, the resulting point pattern cast on the scene depends on 
whether the scanner is set vertically or in some of the tilted positions.

Tilted scanner positions are mostly used to obtain points from the road surface. Tilted scanning plane produces multiple hits from narrow pole structures usually present on the both sides of the road, e.g., traffic signs, light poles and bridge pylons. Such approach allows higher platform speeds than in the use of vertical profile orientation that could miss narrow vertical structures completely. Further advantage of using the tilted scanning plane is the capability of capturing vertical and horizontal edges with equal, angular resolution dependent sampling. Such objects are e.g., corners of buildings and driveways, window and doorframes in the building facades.

\subsection{Trolley MLS for restricted areas}

In some environments and applications a motor powered vehicle is not applicable due to weight, dimensions, noise and exhaust. For such cases the ROAMER can be mounted on a trolley. Trolley provides easy and gentle transportation of the MLS unit around and in the area to be mapped, like urban pedestrian areas and farming, as shown on the right of Figure 1.

Tapiola is one of the main district centres of the city of Espoo, in southern Finland, and it was selected as study area for mobile navigation research conducted by the FGI. Mobile laser scanning data was acquired on May $12^{\text {th }} 2010$ with ROAMER on a trolley with vertical scanning. Scanner head was set to capture $244000 \mathrm{pts} / \mathrm{s}$ with $48 \mathrm{~Hz}$ mirror scan frequency. Tapiola MMS data includes altogether about 160000 profiles; each profile has 5000 points with 3D-position and return intensity producing a point cloud, of which a section is seen in Figure 3. Data collection lasted about one hour, covering an area of $200 \mathrm{~m} \times 300 \mathrm{~m}$, comprising of about $4 \mathrm{~km}$ of street data.

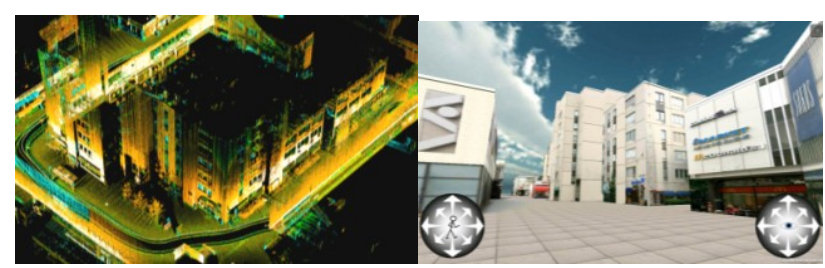

Figure 3. Left: Three-dimensional point cloud from Tapiola, Finland. Right: Photorealistic model of Tapiola processed out from the MLS data and digital imagery (Model image courtesy A. Jaakkola).

Models seen in Figure 3 were reconstructed mainly in fully automated geometry reconstruction from raw laser data to buildings, and corner detection. Process includes also interactive model checking and refining. For the final model the image data was taken separately for textures of building facades due to high buildings and narrow streets. Delineation of the automatic processes used in the point data manipulation is described in detail by (Zhu et al., 2011). Navigable Tapiola model is available at Android Market for free download (http://market.android.com/details?id=com.FGI.Tapiola3D).

\subsection{BOMMS - Fluvial geomorphology research with MLS on boat installation}

The first non-urban application was to put the ROAMER system up on a boat, as in Figure 4. It allows the derivation of detailed riverine topographical data for fluvial applications such as hydraulic modeling and geomorphology. In addition to static modeling of the riverine topography, there is a great need to map the changes in the topography, since the geomorphology and topography of the river channel and surrounding floodplain are affected by the fluvial erosion and deposition processes, which vary from a constant grain-scale displacement to largescale flood-related avulsions (Heritage and Milan, 2009, Cook and Merwade, 2009, Alho and Mäkinen, 2010).

The MLS approach was proven to be an extremely rapid method for surveying riverine topography, taking only 85 minutes to survey a reach approximately six kilometers in length with typical profile density of $401 / \mathrm{m}$. The approach also allows effective survey angle for deep river banks that is difficult to achieve with airborne or terrestrial scanning. The BOMMS system has been used for data acquisitions in numerous studies for hydraulic modeling and analysis of geomorphological processes during the years 2008-2012 (see e.g., Alho et al., 2009, Alho et al., 2011, Vaaja et al., 2011).

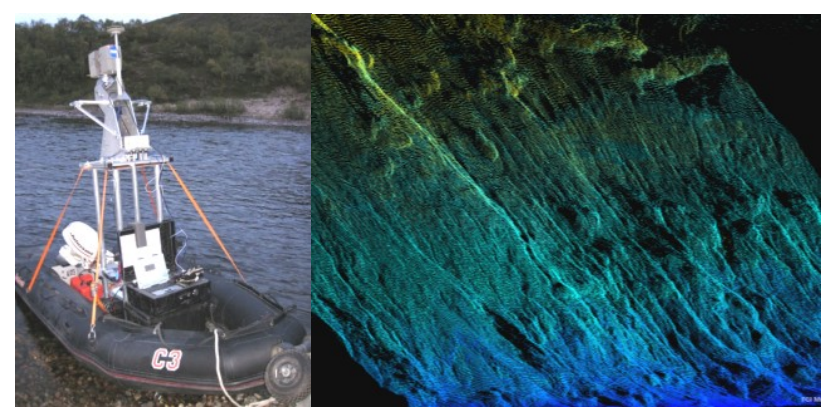

Figure 4. Left: Boat mounted MLS system for mapping of fluvial processes. Right: 20 meters high river bank subject to flood erosion mapped with boat MLS.

The results obtained indicate that MLS could provide accurate and precise change information over large areas. However, data needs to be controlled for systematic errors, as they significantly affect volumes derived from surface analysis.

\subsection{All-terrain MLS in forestry and snow}

In 2010 and 2011 snow data campaigns were conducted, and ROAMER system was utilized for three-dimensional data capture for snow surface characterization. In this application dense point clouds were acquired from a snow mobile installation. Weather conditions where the system was operated were dry and a few degrees below zero. Despite the unconventional operating conditions data shows no degradation in quality or coverage.

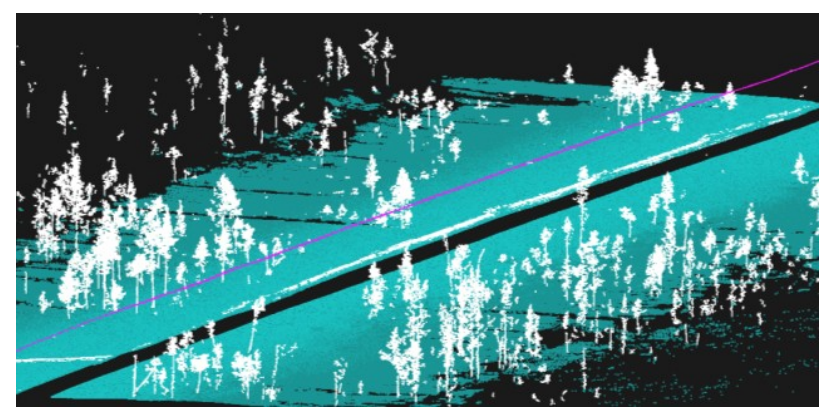

Figure 5. Snow surface classification of MLS data.

With such an arrangement dense and precise, multi-temporal points cloud data over wide areas of snow surface could be produced, as seen from the classified data in Figure 5. The 
longest leg of data was about $11 \mathrm{~km}$ long in the multi-temporal data acquisitions conducted on subsequent days each year. Utilizing MLS the spatial coverage and statistical variation in the data could be dramatically improved compared to traditional methods. Easy applicability allows repeated surveys even for short-term analysis in daily or hour basis.

Snow surface topography and roughness (Kukko et al, 2012) and snow depth change (Kaasalainen et al., 2010) can be studied from the multi-temporal snow surface data. Based on the two season experiences, applying MLS to seasonal snow research seems to be operable and open new ways of producing 3D snow surface characterization.

\subsection{Akhka - Backpack MLS for mobility}

A whole new approach for MLS was built for a study case where the monitoring of Arctic permafrost palsa landforms for climate change studies was urged. Study was conducted in Vaisjeaggi palsa mire close to the Kevo research station, Utsjoki Finland. Backpack MLS solution was needed to overcome the challenges of mobility in marshlands and named as Akhka. Backpack platform could provide mobility and high performance 3D surveying capacity in environments where wheeled vehicles are not possible due to weak ground carrying capacity, narrow passages or other such limits. The scanner head is mounted directly under the IMU unit, and points downwards roughly to an angle of 40 degrees to give crosstrack profiles as shown in Figure 6.

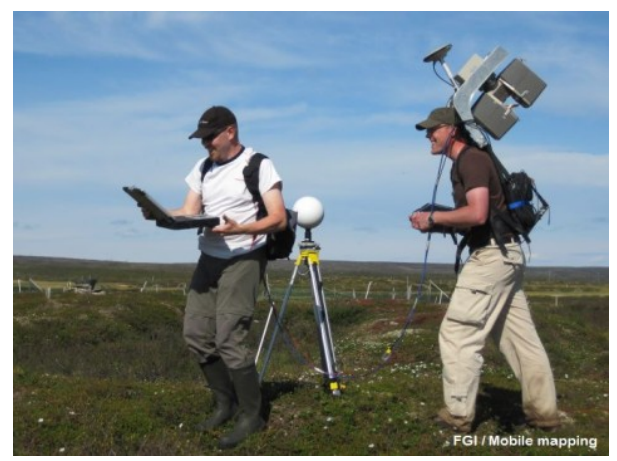

Figure 6. Mapping of permafrost palsa landforms in Finnish Lapland with Akhka backpack mobile laser scanning unit.

A palsa landform area of $50 \mathrm{~m} \times 100 \mathrm{~m}$ was mapped with the Akhka system in June and subsequently in September 2011 for testing the system operability and to analyze the data capability in producing high resolution multi-temporal DEMs for change analysis for climate change network. Figure 7 shows the processed point cloud obtained in September 2011.

Akhka is to our knowledge world widely novel approach to high performance MLS, and it expands the range of applicability of mobile laser scanning technology and allows new insights into research fields that have been lacking of detailed 3D surveying capability with sufficient spatial coverage. It is seen that such MLS systems have a promising potential to speed and intensify the collection of threedimensional survey data and thus widen the spatial coverage of spatial information with remarkable point density and data quality.

\section{PERFORMANCE ANALYSIS}

The performance of ROAMER equipment was verified against MLS test field in a EuroSDR comparison (Kaartinen et al., 2012). As Akhka system utilizes the same navigation and data capturing equipment as the ROAMER, the performance of the systems is expected to correspond to each other. However, the ground velocities for Akhka data collection are typically much slower than for the vehicle mounted ROAMER, and on the other hand steep turns happen more often. Rugged terrain also adds abrupt vertical accelerations to the IMU data. All these factors may have an effect on the quality of navigation solution, and thus an in situ field calibration and control scheme was implemented, for data quality assessment in the field.

\subsection{ROAMER against FGI permanent MLS test field}

For the ROAMER accuracy assessment the test site was surveyed driving the test route in two directions (Clockwise CW and counter-clockwise CCW) in June 2009. Laser profiling was carried out using $48 \mathrm{~Hz}$ scan frequency, and the scanner was measuring profiles tilted to 45 degrees below horizontal to produce the analyzed point cloud.

3.1.1 Cross errors and systematic shifts: The most deviating observations were checked against the ground truth and removed from the analysis if there was any doubt that the error is due to the target, but not due to the system. After that the systematic errors were computed (CCW N: $14 \mathrm{~mm} \mathrm{E}: 5 \mathrm{~mm} \mathrm{~h}$ : $59 \mathrm{~mm}, \mathrm{CW} \mathrm{N}: 25 \mathrm{~mm} \mathrm{E}: 0 \mathrm{~mm} \mathrm{~h}: 43 \mathrm{~mm}$ ) and data was compensated for them.

3.1.2 Accuracy assessment: The results of the analysis are summarized in Table 2. Separate error figures are given for each of the opposite driving directions ( $\mathrm{CCW}, \mathrm{CW})$. Elevation accuracy was analyzed at around 2800 check points resulting to a $20 \mathrm{~mm}$ standard deviation. Planimetric accuracy was evaluated by measuring about 120 reference targets (e.g., building corners, lamp post and other pole center locations and curb corners) in the MLS point clouds and computing the differences in easting and northing. $10 \mathrm{~mm}$ Standard deviation shows a good figure of about the ROAMER system precision, and RMSE level of $23 \mathrm{~mm}$ is a gratifying indicator of the absolute accuracy.

\begin{tabular}{|c|c|c|c|c|}
\hline & \multirow{2}{*}{$\begin{array}{c}\text { Planimetric } \\
\mathrm{CCW}\end{array}$} & \multicolumn{3}{|c|}{ Elevation } \\
\hline & & $\mathrm{CW}$ & CCW & $\mathrm{CW}$ \\
\hline $\mathrm{n}$ & 136 & 120 & 2819 & 2816 \\
\hline Mean & 22 & 18 & - & - \\
\hline Min & 2 & 3 & -68 & -75 \\
\hline Max & 67 & 51 & 60 & 50 \\
\hline Std & 11 & 9 & 20 & 20 \\
\hline RMSE & 25 & 20 & - & - \\
\hline
\end{tabular}

Table 2. Accuracy of the ROAMER data, units in $\mathrm{mm}$.

\subsection{Akhka against field reference}

For assessing the quality estimate for the Akhka data in the field, eight $198.8 \mathrm{~mm}$ spherical reference targets were erected around the Vaisjeaggi study area for September 2011 data acquisition. The location of each sphere center was measured with RTK-GPS, and was extracted automatically from the MLS data for each occasion the target was detected by the scanner. A model sphere was matched by least squares estimation to the point sets to solve the target center location. Systematic shifts were found to be $-3 \mathrm{~mm}$ in easting and $6 \mathrm{~mm}$ in northing, with 
standard deviation of $9 \mathrm{~mm}$ by comparing the coordinates to the RTK-GPS data. In elevation the corresponding values showed $18 \mathrm{~mm}$ systematic and $19 \mathrm{~mm}$ standard deviation. The RMSE for the targets was $18 \mathrm{~mm}$ in horizontal plane, and $29 \mathrm{~mm}$ in elevation. Three-dimensional RMSE for the targets was $34 \mathrm{~mm}$. The values correspond closely to the result for ROAMER.

In Table 3 the "Mean" column describes the average absolute error of MLS point cloud data against RTK-GPS observations, while "Standard deviation" shows the internal precision of the MLS data at each target location. "Maximum error" shows the largest deviation in the data for each of the targets. In general the error figures show a good agreement both internally, but also absolutely to the expected RTK-GPS accuracy levels (10 $\mathrm{mm}+1-2 \mathrm{ppm}$ horizontal and $15-20 \mathrm{~mm}+2 \mathrm{ppm}$ elevation accuracy (Bilker and Kaartinen, 2001)) of the target locations. Internal precision of the target locations derived from the Akhka data indicates good performance being $11 \mathrm{~mm}$ in easting, 13 $\mathrm{mm}$ northing, and $29 \mathrm{~mm}$ in elevation.

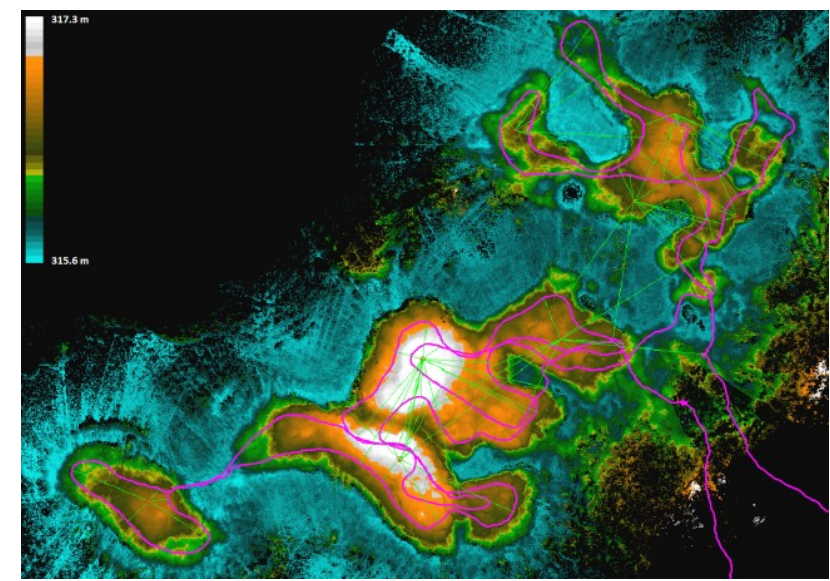

Figure 7. Assessing MLS data accuracy with spherical targets (red circles). Purple line shows the MLS trajectory, green lines connect the targets to trajectory locations from where the targets were detected.

\begin{tabular}{|c|c|c|c|c|c|c|c|c|c|c|}
\hline Target & \multicolumn{4}{c}{ Mean } & \multicolumn{4}{c}{ Standard deviation } & \multicolumn{5}{c|}{ Maximum error } \\
No & $\mathrm{n}$ & $\mathrm{E}$ & $\mathrm{N}$ & $\mathrm{h}$ & $\mathrm{E}$ & $\mathrm{N}$ & $\mathrm{h}$ & $\mathrm{E}$ & $\mathrm{N}$ & $\mathrm{h}$ \\
\hline 1 & 7 & 0.007 & -0.011 & -0.005 & 0.009 & 0.013 & 0.033 & 0.017 & 0.037 & 0.056 \\
2 & 11 & 0.005 & 0.004 & 0.011 & 0.010 & 0.010 & 0.026 & 0.022 & 0.017 & 0.042 \\
3 & 9 & -0.005 & -0.002 & 0.025 & 0.014 & 0.008 & 0.027 & 0.029 & 0.015 & 0.053 \\
4 & 4 & 0.001 & 0.010 & 0.018 & 0.004 & 0.013 & 0.027 & 0.005 & 0.018 & 0.050 \\
5 & 12 & -0.004 & 0.011 & 0.028 & 0.013 & 0.016 & 0.040 & 0.024 & 0.030 & 0.089 \\
6 & 15 & -0.007 & 0.010 & 0.015 & 0.013 & 0.018 & 0.038 & 0.028 & 0.042 & 0.085 \\
7 & 10 & -0.009 & 0.005 & -0.004 & 0.011 & 0.011 & 0.019 & 0.028 & 0.020 & 0.031 \\
8 & 5 & -0.005 & 0.017 & 0.054 & 0.013 & 0.015 & 0.020 & 0.018 & 0.035 & 0.077 \\
\hline
\end{tabular}

Table 3. Internal deviation of the target sphere locations computed from Akhka MLS passes, units in mm, $\mathrm{n}$ shows the number of detections (passes) of each target in the MLS data (E=Easting, N=Northing, h=elevation).

\section{CONCLUSION}

In this paper a variety of different platforms are presented for mobile laser scanning applied to 3D mapping of objects. The ROAMER MLS system was employed in multitude of tasks from urban areas to projects dealing with climate research. The sensor set is the same in all of the approaches, but the carrying vessel and scanning settings were set according to the application and data needs.

The paper also presents a complete new Akhka backpack MLS platform for high performance lidar mapping of areas where it is not possible to operate with any wheeled vehicle. Akhka provides exceedingly high point densities on absolute accuracy level of $20 \mathrm{~mm}$. To our knowledge Akhka is world widely novel approach to high performance MLS and it widens the range of applicability of mobile laser scanning technology. It opens new insights into research fields that have been lacking of detailed 3D surveying capability with sufficient coverage.

The performance of the proposed systems based on analysis on a permanent MLS test field and in situ target field studies show that the systems can produce dense point cloud data for object reconstruction in centimeter level absolute accuracy (horizontal RMSE $23 \mathrm{~mm}$ for ROAMER and $17 \mathrm{~mm}$ for Akhka) both in plane and elevation in good GNSS visibility. Short term relative precision of the data was estimated to be around $12 \mathrm{~mm}$. Error figures for elevation precision were found to be a bit less than double to the horizontal errors, being $14 \mathrm{~mm}$ and $29 \mathrm{~mm}$ for ROAMER and Akhka correspondingly.
It is seen that the proposed MLS approaches have promising potential to speed and intensify the collection of threedimensional survey data. Future applications play a part in various modeling tasks in the vast fields of civil and transportation engineering, archaeology and geomatics, as well as monitoring and understanding of processes in different disciplines of natural sciences such as cryosphere and glaciology, geography, hydrology, silviculture and agriculture.

Future contributions will concentrate on development of automatic data correction and field control schemes. Also a study on correcting the time dependent variations in the trajectory based on the retrieved target data is an issue of future contribution.

\section{REFERENCES}

Alho, P., Kukko, A., Hyyppä, H., Kaartinen, H., Hyyppä, J., Jaakkola, A., 2009. Application of boat-based laser scanning for river survey. Earth Surface Processes and Landforms, 34, pp. 1831-1838.

Alho, P., Mäkinen, J., 2010. Hydraulic parameter estimations of a 2-D model validated with sedimentological findings in the point-bar environment. Hydrol. Process., 24, pp. 2578-2593.

Alho, P., Vaaja, M., Kukko, A., Kasvi, E., Kurkela, M., Hyyppä, J., Hyyppä, H., Kaartinen, H., 2011. Mobile laser scanning in fluvial geomorphology: mapping and change detection of point bars. Zeitschrift fur Geomorphologie, 55(2), pp. 31-50. 
Barber, D. M., Mills, J. P., 2007. Vehicle based waveform laser scanning in a coastal environment. The $5^{\text {th }}$ International Symposium on Mobile Mapping Technology, Pradua, Italy, May 29.-31., 2007.

Bilker, M., Kaartinen, H., 2001. The Quality of Real-Time Kinematic (RTK) GPS Positioning. Reports of the Finnish Geodetic Institute, 1.

Cahalane, C., Mc Elhinney, C.P., McCarthy, T., 2010. Mobile mapping system performance - an analysis of the effect of laser scanner configuration and vehicle velocity on scan. European Lidar Mapping Forum 2010, pp. 1-10.

Connor, L. N., Laxon, S. W., Ridout, A. L., Krabill, W. B., McAdoo, D. C., 2009. Comparison of Envisat radar and airborne laser altimeter measurements over Arctic sea ice, Remote Sens. Environ., 113, pp. 563-570.

Cook, A., Merwade, V., 2009. Effect of topographic data, geometric configuration and modeling approach on flood inundation mapping. J. Hydrol., 377, pp. 131-142.

El-Sheimy, N., 2005. An Overview of Mobile Mapping Systems. FIG Working Week 2005 and GSDI-8, Cairo, Egypt April 16-21, on-line publication, $24 \mathrm{p}$.

Gräfe, G. High precision kinematic surveying with laser scanners. Journal of Applied Geodesy, 1 (4), pp. 185-199.

Heritage, G. L., Milan, D.J., 2009. Terrestrial laser scanning of grain roughness in a gravel-bed river. Geomorphology, 113, pp. 4-11.

Hesse, C., Kutterer, H., 2007. A mobile mapping system using kinematic terrestrial laser scanning (KTLS) for image acquisition. In: Grün, A., and H. Kahmen, (Eds.) 8th Conference on Optical 3-D Measurement Techniques, ETH Zurich, Switzerland, July 9-12, 2007.

Jaakkola, A., Hyyppä, J., Hyyppä, H., Kukko, A., 2008. Retrieval Algorithms for Road Surface Modelling Using LaserBased Mobile Mapping. Sensors, 8, pp. 5238-5249.

Kaasalainen, S., Kaartinen, H., Kukko, A., 2008. Snow cover change detection with laser scanning range and brightness measurements. EARSeL eProceedings, 7, pp. 133-141.

Kaasalainen, S., Kaartinen, H., Kukko, A., Anttila, K., Krooks, A., 2010. Brief Communication: Application of Mobile Laser Scanning in Snow Cover Profiling. The Cryosphere, 5, pp. 135138.

Kaartinen, H., Kukko, A., Hyyppä, J., Lehtomäki, M., 2012. Final report of EuroSDR Commission II project "Mobile Mapping - Road Environment Mapping using Vehicle-based Laser Scanning”. In preparation.

Kukko, A., Hyyppä, J., 2009. Small-footprint Laser Scanning Simulator for System Validation, Error Assessment and Algorithm Development. Photogrammetric Engineering \& Remote Sensing, 75(10), pp. 1177-1189.

Kukko, A., 2009. Road Environment Mapper - 3D data capturing with mobile mapping. Licentiate's Thesis, Helsinki University of Technology, Espoo, Finland, September $17^{\text {th }}$ 2009.
Kukko, A., Andrei, C.-O., Salminen, V.-M., Kaartinen, H., Chen, Y., Rönnholm, P., Hyyppä, H., Hyyppä, J., Chen, R., Haggrén, H., Kosonen, I., Capek, K., 2007. Road Environment Mapping System of the Finnish Geodetic Institute - FGI Roamer, In: The Int. Arch. Photogramm. Remote Sens., XXXVI, pp. 241-247.

Kukko, A., Jaakkola, A., Lehtomäki, M., Kaartinen, H., 2009. Mobile mapping system and computing methods for modelling of road environment. 2009 Urban Remote Sensing Joint Event, Shanghai, China, 20.-22. May 2009.

Kukko, A., Anttila, K., Manninen, T., Kaartinen, H., Kaasalainen, S., 2012. Snow surface roughness from mobile laser scanning data. Manuscript in preparation.

Lehtomäki, M., Jaakkola, A., Hyyppä, J., Kukko, A., Kaartinen, H., 2010. Detection of Vertical Pole-Like Objects in a Road Environment Using Vehicle-Based Laser Scanning Data, Remote Sensing, 2(3), pp. 641-664.

Lehtomäki, M., Jaakkola, A., Hyyppä, J., Kukko, A., Kaartinen, H., 2011. Performance analysis of a pole and tree trunk detection method for mobile laser scanning data. Proceedings of ISPRS Workshop Laser Scanning 2011, Calgary, Canada 29-31 August.

Liu, Z., Chen, Y., Qin, Y., Chen, R., Kuittinen, R., Zhu, L., Pei, L., Hyyppä, J., Zhang, J., Liu, J., Wang, J., Takala, J., Leppäkoski, H., Kuusniemi, H., 2010. Moving to 3D Nav - For Smartphone LBS, GPS World, 2, pp. 14-18.

Petrie, G., 2010. An introduction to technology Mobile Mapping systems, GeoInformatics, 13(1), pp. 32-43.

Vaaja, M., Hyyppä, J., Kukko, A., Kaartinen, H., Hyyppä, H., Alho, P., 2011. Mapping Topography Changes and Elevation Accuracies Using a Mobile Laser Scanner. Remote Sensing, 3(3), pp. 587-600.

Yoo, H. J., Goulette, F., Senpauroca, J., Lepère, G., 2010. Analysis and improvement of laser terrestrial mobile mapping systems configurations. ISPRS Commission V Symposium, Newcastle upon Tyne, UK. 2010, In: The Int. Arch. Photogramm. Remote Sens., XXXVIII, Part 5, pp. 633-638.

Zhao, H., Shibasaki, R., 2003. Reconstructing a textured CAD model of an urban environment using vehicle-borne laser range scanners and line cameras. Machine Visions and Applications, 14(1), pp. 35-41.

Zhu, L., Hyyppä, J., Kukko, A., Kaartinen, H., Chen, R., 2011. Photorealistic building reconstruction from mobile laser scanning data, Remote Sensing, 3(7), pp. 1406-1426.

\section{ACKNOWLEDGEMENTS}

The development and research presented has been funded by the Academy of Finland through projects "Transportation Data Acquisition by Means of ICT-derived 3D Modeling", "Improving the Forest Supply Chain by means of Advanced Laser Measurements" and "Science and Technology Towards Precision Forestry", by the Finnish Funding Agency for Technology and Innovation through projects "Development of Automatic, Detailed 3D Model Algorithms for Forests and Built Environment" and GIFLOOD, and by Maj and Tor Nessling Foundation on FLOODAWARE project. 